\title{
Linking melanism to brain development: expression of a melanism-related gene in barn owl feather follicles covaries with sleep ontogeny
}

\author{
Madeleine F Scriba ${ }^{1,2 \dagger}$, Anne-Lyse Ducrest ${ }^{2+}$, Isabelle Henry ${ }^{2}$, Alexei L Vyssotski ${ }^{3}$, Niels C Rattenborg ${ }^{1 *+}$ \\ and Alexandre Roulin ${ }^{2 * \dagger}$
}

\begin{abstract}
Background: Intra-specific variation in melanocyte pigmentation, common in the animal kingdom, has caught the eye of naturalists and biologists for centuries. In vertebrates, dark, eumelanin pigmentation is often genetically determined and associated with various behavioral and physiological traits, suggesting that the genes involved in melanism have far reaching pleiotropic effects. The mechanisms linking these traits remain poorly understood, and the potential involvement of developmental processes occurring in the brain early in life has not been investigated. We examined the ontogeny of rapid eye movement (REM) sleep, a state involved in brain development, in a wild population of barn owls (Tyto alba) exhibiting inter-individual variation in melanism and covarying traits. In addition to sleep, we measured melanistic feather spots and the expression of a gene in the feather follicles implicated in melanism (PCSK2).
\end{abstract}

Results: As in mammals, REM sleep declined with age across a period of brain development in owlets. In addition, inter-individual variation in REM sleep around this developmental trajectory was predicted by variation in PCSK2 expression in the feather follicles, with individuals expressing higher levels exhibiting a more precocial pattern characterized by less REM sleep. Finally, PCSK2 expression was positively correlated with feather spotting.

Conclusions: We demonstrate that the pace of brain development, as reflected in age-related changes in REM sleep, covaries with the peripheral activation of the melanocortin system. Given its role in brain development, variation in nestling REM sleep may lead to variation in adult brain organization, and thereby contribute to the behavioral and physiological differences observed between adults expressing different degrees of melanism.

Keywords: REM sleep, Melanocortin, Melanism, Pleiotropy, Ontogeny, Development, Avian

\section{Introduction}

Historically, the potential link between melanism and behavior has been the subject of both scientific and superstitious discussions [1]. In several species, including humans, the degree of melanism is due to genetic variation in the melanocortin 1 receptor (MC1R) that binds the peptide $\alpha$-melanocyte-stimulating hormone $(\alpha-\mathrm{MSH})$ involved in eumelanin pigment deposition in the skin

\footnotetext{
*Correspondence: Rattenborg@orn.mpg.de; Alexandre.Roulin@unil.ch ${ }^{\dagger}$ Equal contributors

${ }^{1}$ Avian Sleep Group, Max Planck Institute for Ornithology,

Eberhard-Gwinner-str.11, Seewiesen 82319, Germany

2Department of Ecology and Evolution, University of Lausanne, Lausanne

1015, Switzerland

Full list of author information is available at the end of the article
}

$[2,3]$. However, relatively few pleiotropic effects of the $M C 1 R$ gene have been described [2,4]. In contrast, in many other species, a suite of behavioral and physiological traits covary with the degree of melanism [5]. For example, in barn owls, the degree of eumelanin feather spotting covaries with anti-predator responses [6], natal dispersal [7], reproductive activity [8], parasite resistance [9], and the regulation of glucocorticoids [10] and energy [11]. The covariation between melanism and these traits suggests that the genes involved have multiple pleiotropic effects that extend well beyond pigmentation [12].

The mechanisms linking melanism to these behavioral and physiological traits remain unresolved [5]. Genetic

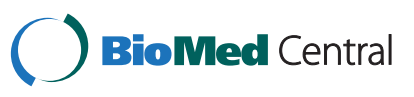


variation in the regulation of hormone and neurotransmitter levels may have direct effects on melanism and other phenotypes in adults [13]. In addition, genetic variation in hormone and neurotransmitter levels might affect adult phenotypes indirectly by acting on developmental processes early in life that influence brain organization. Conversely, genetically determined variation in developmental processes occurring in the brain might determine how hormones and neurotransmitters are regulated in adults. As a first step toward understanding whether developmental processes occurring in the brain contribute to behavioral and physiological differences associated with melanism in adults, we investigated whether the level of a gene involved in melanism expressed in the skin and feathers covaries, not only with peripheral pigmentation, but also with developmental processes occurring in the central nervous system. Instead of following the traditional genetic approach of studying inbred albino and pigmented rodent strains in captivity $[14,15]$, we studied naturally occurring variation in melanism in barn owls in the wild (Figure 1a-d) where they are subject to natural selection, a key to understanding the evolution of such biological traits [16]. To measure ongoing brain development, we focused on sleep because it provides a window into the developing brain [17], which can be viewed using minimally-invasive electroencephalographic (EEG) methods in the wild [18] (Figure 1e,f).

Mammals and birds exhibit two types of sleep, rapid eye movement (REM) and non-REM sleep distinguished from each other and wakefulness using a combination of behavioral and neurophysiological features [20]. In contrast to non-REM sleep, the EEG during REM sleep shows a pattern remarkably similar to that occurring during wakefulness. Despite this awake-like brain activity, the animal is behaviorally asleep with closed eyes and minimal awareness of its surroundings. In mammals, the amount of time spent in REM sleep is highest in young animals, and then gradually declines to adult levels [21-24]. In altricial mammals - those born with relatively immature brains and dependent upon parental care - this occurs before and after birth [21-24], whereas in precocial mammals - those born with relatively mature brains and less dependent upon parental care - the decline in REM sleep occurs primarily before birth [25-29]. Similar age-related declines in REM sleep have been reported in birds [30-32], but the evidence remains contradictory across studies [33] and confounded by factors other than age that might influence REM sleep (e.g., temperature [34], see Discussion). In mammals, the age-related decline in REM sleep and subsequent experimental work $[17,35]$ suggest that the awake-like brain activity occurring during REM sleep plays a role in directing brain development [21]. However, the exact role that REM sleep plays in brain development remains unresolved.
The aims of this study were to determine whether the ontogeny of avian sleep follows a mammalian-like trajectory characterized by an age-related decline in REM sleep and to examine whether variation in this developmental process occurring in the brain covaries with components of the melanocortin system expressed in the periphery. For the later we measured in the feather follicles of barn owl nestlings the expression of PCSK2 - the gene that encodes the proprotein convertase subtilisin/kexin type 2 (PCSK2) responsible for $\alpha$-MSH synthesis [36] - and its relationship to eumelanin-based feather spotting. Herein we find that 1) REM sleep declines with age in owls, as in mammals, 2) variation around this developmental trajectory is predicted by the expression of PCSK2 in feather follicles, and 3) PCSK2 expression predicts eumelaninbased feather spotting. Collectively, these findings demonstrate an unprecedented link between melanism and developmental processes occurring in the brain.

\section{Results}

\section{Sleep ontogeny}

The 66 barn owl nestlings were awake approximately half of the time (54.6\%, range: $45.3-62.9 \%)$, in nonREM sleep 33.0\% (25.1 - 42.7\%), and in REM sleep $12.4 \%(7.7-17.6 \%)$. The mean duration of wakefulness bouts was $50.7 \pm 2.0(24.3-118.2)$ sec, of non-REM sleep $17.1 \pm 0.4(11.6-25.3) \mathrm{sec}$, and of REM sleep 12.0 $\pm 0.2(8.8-16.5) \mathrm{sec}$. Although the time spent in wakefulness and non-REM sleep did not change significantly with age (Table 1, Figure 2a,b), the duration of bouts of wakefulness and non-REM sleep increased with age (Table 1, Figure 2d,e). Because wakefulness and nonREM sleep mean bout durations were correlated $(r=0.63$, $n=66, p<0.0001$ ), we tested whether the relationship between age and non-REM sleep mean bout duration was confounded by wakefulness mean bout duration in a multiple regression analysis. This was not the case as the relationship between age and non-REM sleep mean bout duration was still significant $\left(F_{1,63}=5.31, p=0.025\right)$. In contrast, the relationship between age and wakefulness mean bout duration was no longer significant when nonREM sleep mean bout duration was added in the same model $\left(F_{1,63}=2.11, p=0.15\right)$. This suggests that the relationship between wakefulness mean bout duration and age is mediated indirectly by the relationship between age and non-REM sleep mean bout duration.

Time spent in REM sleep declined with age (Table 1, Figure 2c), a relationship that was even stronger when REM sleep was expressed as a percentage of the total time spent sleeping (Pearson's correlation: $r=-0.44$, $p=0.0002$ ). Because the duration of REM sleep bouts did not change with age (Table 1, Figure 2f), this agerelated decline in time spent in REM sleep reflects a reduced propensity to initiate bouts of REM sleep. This 

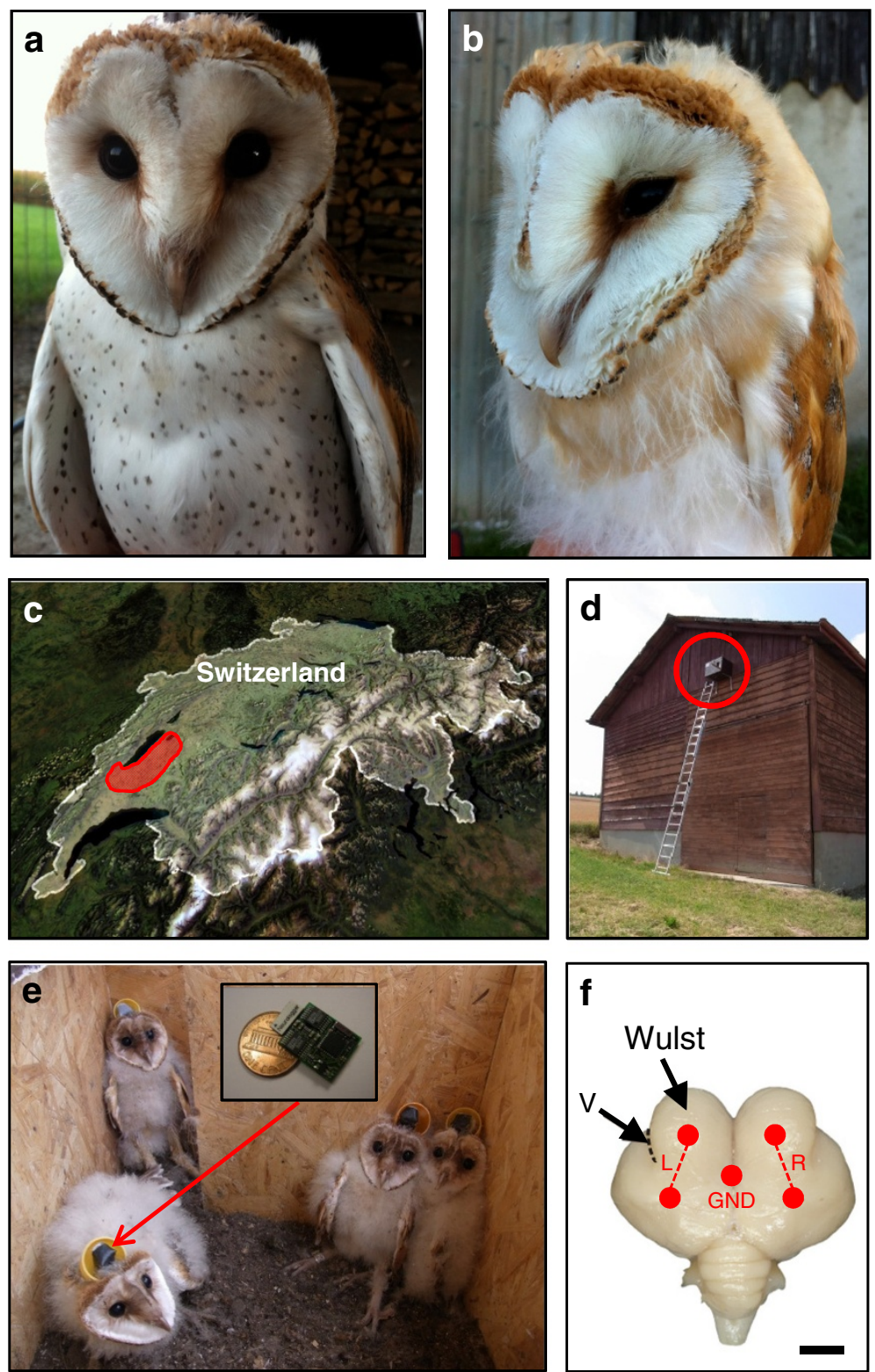

Figure 1 Study animals, setting, and neurophysiological methods. Barn owl nestlings displaying high (a) and low (b) levels of eumelanin spotting, (c) satellite image of Switzerland showing the study area shaded in red, (d) a nest box hanging on a typical barn, (e) nestlings with an EEG/accelerometer logger (inset) attached to their heads, and (f) dorsal view of an adult barn owl brain (anterior up) showing the relative location of electrodes (red spots) and bipolar EEG derivations (red dashed lines) for the left $(L)$ and right (R) hemispheres $(b a r=0.5 \mathrm{~cm})$; the vallecula groove $(V)$ marks the lateral boundary of the hyperpallium, or Wulst. a and b, images by AR; $c$, image from NASA; $d$ and e, images by MFS (inset by ALV); and f, modified from Martin et al. [19] with permission.

propensity was also reflected in a significant age-related increase in the time from sleep onset to the onset of REM sleep (i.e., REM sleep latency) (Table 1, Figure 2g).

\section{Relationship between sleep ontogeny and PCSK2 expression}

We next examined the relationship between these ontogenetic patterns occurring in the brain and PCSK2 expression in feather follicles. The level of PCSK2 expression increased with nestling age (linear mixed model with the random variable nest of rearing explaining $22.36 \%$ of the variance: $F_{1,122.9}=6.50, p=0.012$ ), but was not associated with nestling sex $\left(F_{1,121.5}=0.34, p=0.56\right)$, date $\left(F_{1,38.35}=\right.$ $0.02, p=0.89)$, and time of the day when feathers were collected $\left(F_{1,72.77}=0.71, p=0.40\right.$; all two-way interactions with sex were not significant, $p>0.15$ ). Although the time spent in wakefulness and the duration of wakefulness bouts were not correlated with PCSK2 expression (Table 1 , 
Table 1 Relationships between sleep-wakefulness, age, and PCSK2 expression

\begin{tabular}{|c|c|c|c|c|c|c|c|}
\hline & \multicolumn{2}{|c|}{ Wakefulness } & \multicolumn{2}{|c|}{ Non-REM sleep } & \multicolumn{3}{|c|}{ REM sleep } \\
\hline & Percent & Bout Duration & Percent & Bout Duration & Percent & Bout Duration & Latency \\
\hline \multirow[t]{2}{*}{ Age (sleep) } & $F_{1,48.96}=0.02$ & $F_{1,58.75}=10.69$ & $F_{1,43.15}=2.48$ & $F_{1,52.88}=11.83$ & $F_{1,55.09}=5.87$ & $F_{1,46.09}=0.001$ & $F_{1,61.52}=19.46$ \\
\hline & $p=0.89$ & $p=0.002$ & $p=0.12$ & $p=0.001$ & $p=0.019$ & $p=0.97$ & $p<0.0001$ \\
\hline \multirow[t]{2}{*}{ Age (PCSK2) } & $F_{1,54.71}=0.05$ & $F_{1,52.38}=0.05$ & $F_{1,53.97}=0.005$ & $F_{1,52.13}=0.003$ & $F 1,52.28=0.39$ & $F_{1,56.95}=0.40$ & $F_{1,51.86}=0.002$ \\
\hline & $p=0.83$ & $p=0.82$ & $p=0.95$ & $p=0.96$ & $p=0.53$ & $p=0.53$ & $p=0.97$ \\
\hline \multirow[t]{2}{*}{ PCSK2 } & $F_{1,57.86}=0.47$ & $F_{1,56.71}=1.19$ & $F_{1,58.22}=5.14$ & $F_{1,57.95}=3.66$ & $F_{1,57.36}=6.39$ & $F_{1,58.91}=8.49$ & $F_{1,57.92}=2.67$ \\
\hline & $p=0.49$ & $p=0.28$ & $p=0.027$ & $p=0.06$ & $p=0.014$ & $p=0.005$ & $p=0.11$ \\
\hline \multirow[t]{2}{*}{ Sex } & $F_{1,52.46}=0.0001$ & $F_{1,52.96}=0.03$ & $F_{1,49.1}=0.002$ & $F_{1,53.64}=0.02$ & $F_{1,53.00}=0.10$ & $F_{1,54.10}=0.21$ & $F_{1,54.83}=0.26$ \\
\hline & $p=0.99$ & $p=0.88$ & $p=0.97$ & $p=0.88$ & $p=0.75$ & $p=0.65$ & $p=0.61$ \\
\hline \multirow[t]{2}{*}{ Date } & $F_{1,30.2}=2.49$ & $F_{1,26.43}=1.25$ & $F_{1,25.28}=1.97$ & $F_{1,23.86}=0.03$ & $F_{1,25.72}=1.52$ & $F_{1,29.38}=2.09$ & $F_{1,22.89}=0.06$ \\
\hline & $p=0.13$ & $p=0.27$ & $p=0.17$ & $p=0.87$ & $p=0.23$ & $p=0.16$ & $p=0.81$ \\
\hline \multirow[t]{2}{*}{ Temperature (mean) } & $F_{1,33.29}=0.27$ & $F_{1,33.49}=0.12$ & $F_{1,30.78}=0.14$ & $F_{1,32.94}=0.50$ & $F_{1,36.84}=2.16$ & $F_{1,30.47}=0.003$ & $F_{1,32.81}=0.81$ \\
\hline & $p=0.60$ & $p=0.73$ & $p=0.71$ & $p=0.49$ & $p=0.15$ & $p=0.96$ & $p=0.37$ \\
\hline Nest (\% variance) & 15.7 & 14.5 & 1.1 & 14.4 & 22.3 & 8.5 & 22.3 \\
\hline
\end{tabular}

Linear mixed models for the relationships between the percentage of time spent in and mean bout duration of each state, and expression of $P C S K 2$ in feather follicles. For REM sleep, the mean latency from sleep onset is also shown. Nest of rearing was set as a random variable. The variables "Age (sleep)" and "Age (PCSK2)" are the ages when we measured nestling sleep and PCSK2 expression, respectively. Significant results of final models are highlighted in bold. The other variables were backward removed starting with the least significant ones. Also shown is the percentage of variance explained by the random factor nest of rearing. This value indicates the extent to which sleep variables of different nest-mates are similar. Mean temperature did not correlate with any sleep variable (see also Additional file 1: Figure S3).

Figure 3a,d), time spent in non-REM sleep and the duration of non-REM sleep bouts were positively correlated with PCSK2 expression (Table 1, Figure 3b,e). In contrast, the time spent in REM sleep and the duration of REM sleep bouts were strongly negatively correlated with PCSK2 expression (Table 1, Figure 3c,f), suggesting that part of the age-related decline in REM sleep was associated with PCSK2 expression. Finally, REM sleep latency was not correlated with PCSK2 expression (Table 1, Figure 3g). Importantly, none of the sleepwakefulness variables was correlated with the age when PCSK2 was measured (Table 1), which differed from the age when sleep was measured, indicating that the associations between these variables and PCSK2 were not due to simple covariation between age and PCSK2 expression. Collectively, these findings suggest that the propensity to initiate bouts of REM sleep declines with age, whereas the propensity to terminate bouts of REM sleep increases with PCSK2 expression. Thus, age and PCSK 2 expression, or covarying processes, influence different aspects of REM sleep during development.

\section{Genetic basis of eumelanin feather spottiness}

On average nestlings displayed $40.5 \pm 1.6$ spots (range: 0 - 76) measuring $1.45 \pm 0.05 \mathrm{~mm}$ (range: $0-2.38$ ), breeding females $44.5 \pm 2.5$ spots (range: $14-76$ ) measuring $1.74 \pm 0.09 \mathrm{~mm}$ (range: $0.86-3.00$ ) and breeding males $38.4 \pm 4.4$ spots (range: $0-88$ ) measuring $1.27 \pm$ $0.10 \mathrm{~mm}$ (range: $0-2.38$ ). There was no evidence of assortative mating with respect to spotting (Pearson's correlations between mother and father spottiness: $r=0.02, p=0.94)$. Furthermore, biological and foster parents did not resemble each other with respect to plumage traits (Pearson's correlations: $p$-values $>0.31$ ). In line with the assumption that the expression of feather spots is under genetic control, spottiness in the cross-fostered nestlings was strongly correlated with maternal (Pearson's correlation based on mean sibling values: $r=0.49, n=24, p=0.015)$ and paternal spottiness $(r=0.53, n=18, p=0.023)$.

\section{Feather PCSK2 expression and eumelanin spottiness}

In cross-fostered nestlings, PCSK2 expression was positively associated with nestling eumelanin spottiness (Figure 4; linear mixed model with nest of rearing as the random variable: nestling spottiness: $F_{1,49.58}=8.71$, $p=0.005$; age when PCSK 2 was measured: $F_{1,70.8}=1.73$, $p=0.20$; interaction: $\left.F_{1,66.69}=0.39, p=0.53\right)$. Thus, PCSK2 expression in feather follicles is correlated with both the ontogeny of sleep and melanic feather spotting in nestlings.

\section{Discussion}

In this study, we demonstrate a previously unrecognized link between developmental processes occurring in the central nervous system and processes involved in melanism occurring in the periphery. Sleep ontogeny in owlets undergoing a period of brain growth followed a mammalian-like pattern [24] characterized by an agerelated increase in the duration of bouts of wakefulness and non-REM sleep. Also as in mammals, REM sleep 

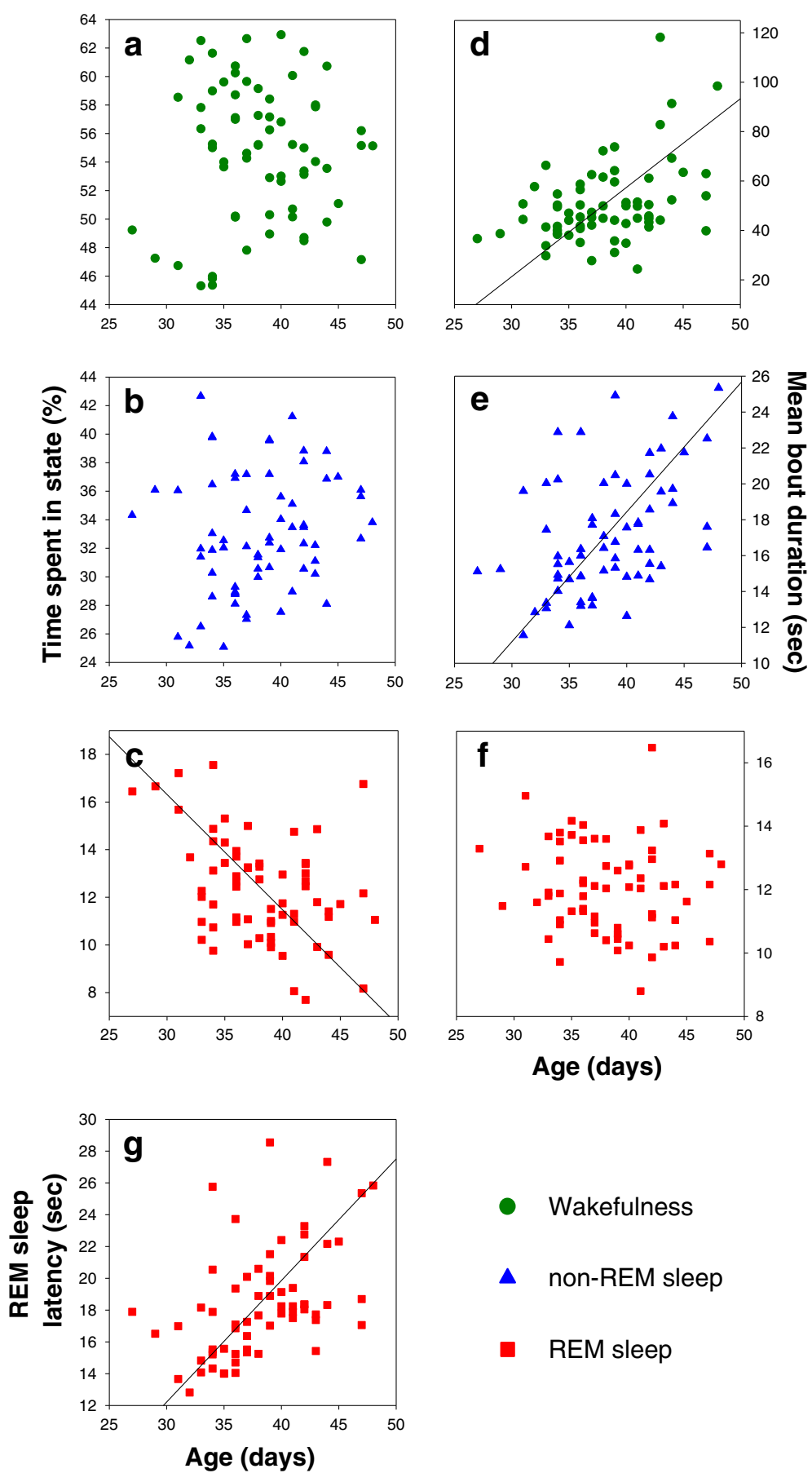

- Wakefulness

- non-REM sleep

REM sleep

Figure 2 Time spent in sleep-wakefulness states and mean bout durations are age-dependent. Time spent in (a) wakefulness, (b) nonREM sleep, and (c) REM sleep, mean bout durations for (d) wakefulness, (e) non-REM sleep, and (f) REM sleep, and (g) mean REM sleep latency $(n=66)$. The following correlations with age were statistically significant: duration of bouts of wakefulness (Pearson's correlation: $r=0.41, p=0.0006)$ and non-REM sleep $(r=0.46, p=0.0001)$, time spent in REM sleep $(r=-0.40, p=0.0008)$, and mean REM sleep latency $(r=0.47, p<0.0001)$. None of the other variables correlated significantly with age ( $p$-values $>0.18$ ). Similar results were obtained when we calculated mean values for each nest.

time and latency decreased and increased, respectively, as the owlets aged [24]. For REM sleep, in particular, this developmental trajectory covaried strongly with PCSK2 expression in the feather follicles, with owlets expressing higher PCSK2 showing lower amounts of REM sleep, a more precocial pattern (Figure 5). Finally, eumelaninbased spottiness was genetically determined and positively correlated with PCSK2 expression in feather follicles. 

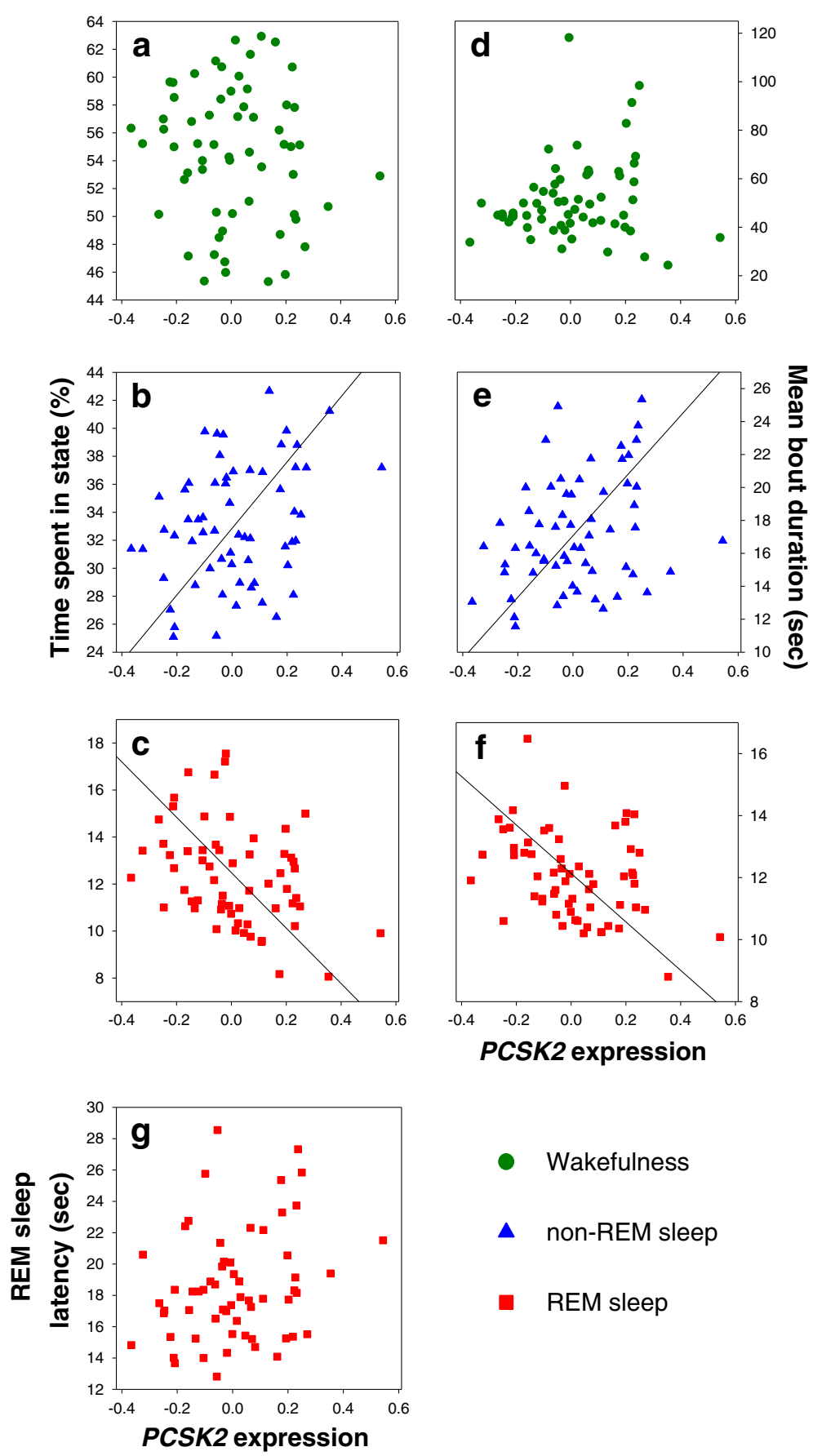

- Wakefulness

- non-REM sleep

- REM sleep

Figure 3 Time spent in sleep-wakefulness states and mean bout durations correlate with PCSK2 expression in feather follicles. Time spent in (a) wakefulness, (b) non-REM sleep, and (c) REM sleep, mean bout durations for (d) wakefulness, (e) non-REM sleep, and (f) REM sleep and $(\mathbf{g})$ mean REM sleep latency $(n=61)$. The following correlations with PCSK2 expression were statistically significant: time spent in non-REM sleep (Pearson's correlation: $r=0.30, p=0.019)$ and duration of bouts of non-REM sleep ( $r=0.29, p=0.023$; see also analysis in Table 1 where this relationship is only a trend), time spent in REM sleep $(r=-0.36, p=0.005)$, and duration of bouts of REM sleep $(r=-0.35, p=0.006)$. None of the other variables correlated significantly with PCSK2 expression ( $p$-values $>0.23$ ). Similar results were obtained when we calculated mean values for each nest.

Sleep ontogeny: comparison with prior research

While it is often stated that the amount of REM sleep is higher in young birds when compared to adults [37], a review of the literature reveals that this issue is far from resolved. Prior to our study, the ontogeny of REM sleep had been examined in only two avian species, the 


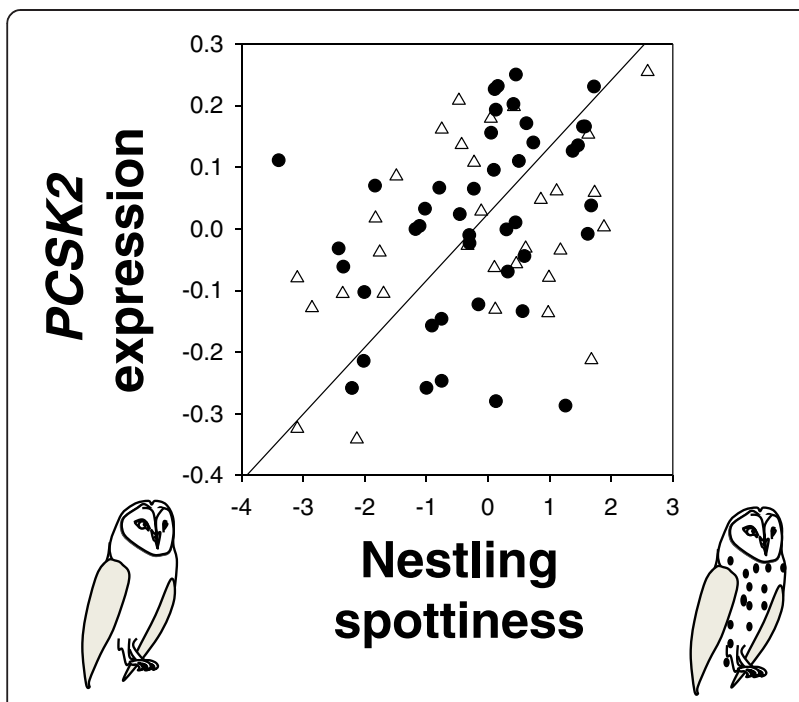

Figure 4 Nestling spottiness correlates positively with PCSK2 expression in feather follicles. Data for male (triangles) and female (circles) cross-fostered nestlings. PCSK2 expression was positively correlated with nestling spottiness (Pearson's correlation: $r=0.39$, $n=75, p=0.0006$ ).

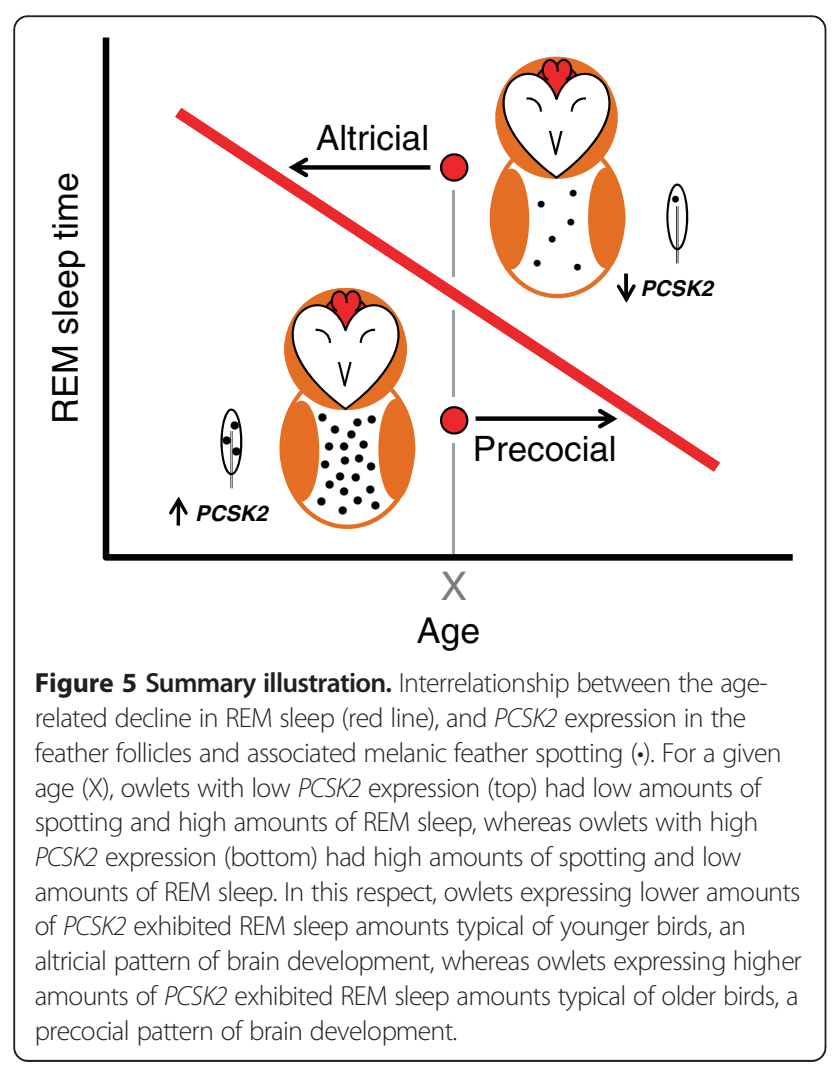

precocial chicken (Gallus gallus domesticus) and the altricial magpie (Pica pica). However, the results remain contradictory and/or confounded by environmental factors known to influence the expression of REM sleep. While REM sleep can be first identified $1-2 \mathrm{~d}$ before chicken embryos hatch [38,39], age-related changes in REM sleep have been examined primarily following hatching. Several studies have reported that REM sleep as a \% of total sleep time (\%REM sleep) declines with age from higher amounts occurring shortly $(0-8 \mathrm{~h})$ after hatching [30,31,40,41]. However, others have reported lower \%REM sleep in newly hatched chicks [33]. Multiple potentially interacting factors may contribute to the variability in reports of REM sleep ontogeny in chickens. As noted by Schlehuber et al. [33], when compared to older chicks, EEG activity during REM sleep was less differentiated from that occurring during non-REM sleep in newly hatched chicks (see also [42]). As a result, this may have led to different interpretations as to what constitutes REM sleep. A similar issue has also contributed to the debate over when REM and non-REM sleep are first distinguishable from one another in mammals [43,44]. In addition, in chickens, the amount of REM sleep recorded at different time points in the various studies could have been influenced by, 1) the time from surgery to the first recordings (i.e., short in newly hatched chicks), 2) the brain regions recorded, 3) the social conditions (isolated or in groups) in the recording environment, and 4) exposure to potential imprinting stimuli, such as the experimenter. Indeed, after most ontogenetic work on chicks had been conducted, it was shown that exposure to a visual imprinting stimulus after hatching caused an increase in REM sleep [45]. Finally, a general concern regarding examining the ontogeny of REM sleep in recently hatched chicks is the possibility that the process of hatching itself causes a temporary increase or decrease in REM sleep that masks its true relationship (or lack thereof) with brain development. This is potentially particularly problematic in precocial species, such as chickens, if they exhibit a mammalian-like pattern of attaining adult REM sleep levels shortly after hatching.

In the only prior study examining the development of sleep in an altricial bird, Szymczak reported lower \% REM sleep in adult ( 1 - 2-year-old) magpies when compared to independent juveniles (3.5 - 4.0-month-old) [32], a pattern seemingly comparable to that observed in altricial mammals. However, the juveniles were recorded under warmer ambient temperatures than the adults. This difference confounds the interpretation of these results because, as in mammals, avian REM sleep is suppressed by low ambient temperatures [46,47]. Indeed, in a subsequent study, Szymczak showed that the low temperatures experienced by the adult magpies in the 
earlier study also suppress REM sleep in this species [34]. Given these concerns regarding prior ontogenetic studies in chickens and magpies, our finding of a temperature-independent (Table 1), age-related decline in REM sleep in barn owl nestlings is to our knowledge the first unequivocal evidence for this mammalian-like pattern in birds. The presence of this pattern in mammals and birds suggests that it reflects a fundamental aspect of sleep in animals that exhibit REM sleep.

\section{Linking sleep ontogeny to peripheral PCSK2 expression}

How might PCSK2 expression in feather follicles be related to the ontogeny of sleep in the brain? Although peptides produced by PCSK 2 processing in the follicle $(\alpha-\mathrm{MSH}$ and corticotropin-like intermediate lobe peptide (CLIP)) might reach the brain [48] and thereby influence regions regulating sleep, the effects that these compounds have on sleep when injected intracerebralventricularly (icv) in adult mammals are inconsistent with this bottom-up scenario. Whereas higher PCSK2 expression was associated with less REM and more non-REM sleep in owls, both sleep states decreased and wakefulness increased following $\alpha-\mathrm{MSH}(0.5-50 \mu \mathrm{g})$ injection in rabbits [49]. In rats, although a low dose (1 ng) of $\alpha-\mathrm{MSH}$ increased non-REM sleep [50], higher doses $(0.05-6.0 \mu \mathrm{g})$ had no affect on sleep or wakefulness [51]. Moreover, in all studies, REM sleep increased following injection of CLIP in rats [50,52-54]. In addition, whereas the duration of bouts of REM sleep decreased with increasing PCSK2 expression in owls, CLIP increased the duration of REM sleep bouts in rats [53]. To the extent that these findings in adult mammals receiving icv injections of $\alpha-\mathrm{MSH}$ and CLIP translate to young owls, they do not support the notion that the production of these peptides in the follicles accounts for the relationships observed between PCSK2 expression and sleep.

Alternatively, increased levels of monoamine neurotransmitters known to suppress REM sleep in mammals and birds [55] might also increase the release of hormones from the hypothalamic-pituitary-adrenal (HPA) and -thyroid (HPT) axes, resulting in activation of peripheral components of the melanocortin system [13]. Because the HPA hormone adrenocorticotropic hormone $(\mathrm{ACTH})$ is the precursor that PCSK2 processes into $\alpha$ $\mathrm{MSH}, \mathrm{ACTH}$ released into the circulation may reach the follicle and lead to increased PCSK2 expression. In addition to the potential direct effects that monoamine neurotransmitter levels might have on brain regions controlling REM sleep, they may also influence REM sleep amounts indirectly via activation of the HPT axis. Thyroid hormones produced in the thyroid gland (via the HPT axis) play an important role in brain development and its timing [56-60]. Consequently, increased levels of thyroid hormones might accelerate brain development, and thereby account for the precocial agerelated decline in REM sleep observed in owlets with high levels of peripheral PCSK2 expression. Finally, given that PCSK2 is involved in processing neuropeptides in the periphery (e.g., insulin) and brain (e.g., thyroid releasing hormone) involved in brain development [61-63], the relationship between peripheral PCSK2 expression and REM sleep might arise if genetic polymorphisms in transcription factor binding sequences of PCSK2, or transcription factors regulating the expression [64], stability, or splicing of PCSK2 affect its expression throughout the body and brain in a coordinated manner. The finding that the relationship between PCSK2 expression and feather spotting did not vary with age (the interaction between nestling spottiness and nestling age on PCSK2 expression was not significant, $p=0.86$ ) suggests that $P C S K 2$ expression was not locally regulated exclusively with regard to the feather formation process, but instead may have been determined by global regulatory mechanisms both during and outside the period of feather formation. Regardless of the exact mechanism(s) responsible for the strong link between peripheral PCSK2 expression and REM sleep, this variation in the amount of REM sleep likely reflects and/or mediates developmental processes occurring in the brain.

\section{Evolutionary considerations}

The covariation between pigmentation, peripheral PCSK2 expression, and sleep ontogeny observed in barn owls in nature may be maintained by trade-offs related to varying the pace of brain development. Owlets that expressed higher levels of PCSK2 in the feather follicles exhibited REM sleep amounts typical of older owlets. To the extent that the amount of REM sleep predicts brain development in owls, this suggests that brain development is more precocial in these individuals. Among birds, precocial species tend to have smaller brains for their size than altricial species [65], and species with bigger brains engage in more innovative feeding behaviors [66] and survive longer in nature [67]. If such relationships exist in barn owls, the apparent cost of precocial brain development may be balanced by other beneficial traits associated with melanism, including enhanced anti-inflammatory responses and better regulation of the balance between food intake and energy expenditure [12]. Ultimately, brain imaging studies are needed to establish whether and how this link between the periphery and the developing brain influences adult brain organization, behavior, and physiology. Finally, in addition to potentially influencing adult behavior and physiology via brain development, variation in REM sleep may also influence these traits more directly if it persists into adulthood [68]. 


\section{Conclusions}

We demonstrate that the pace of brain development, as reflected in age-related changes in sleep, covaries with the peripheral activation of the melanocortin system. Although the mechanisms linking these processes remain unresolved, our findings suggest a previously unrecognized pathway that may account for the link between melanism and a variety of behavioral and physiological phenotypes in adults. Specifically, variation in developmental processes occurring in the brain linked to melanism may influence adult brain organization and thereby its regulation of behavior and physiology. In this respect, our findings move the field forward by establishing a new framework for investigating how and why pigmentation is often predictive of other seemingly unrelated phenotypes. More generally, our findings expand our understanding of the breadth of the interface between the central nervous system and the rest of the body.

\section{Methods and materials General procedures}

In 2011 we studied a population of free-living barn owls in Switzerland (Figure 1c). Our aim was to examine potential mechanisms that link a peripheral trait (i.e., eumelanin-based black feather spots; Figure 1a,b) with developmental processes taking place in the central nervous system (i.e., sleep), not only at the precise time when coloration is produced, but also outside this period, as many of the associations between spottiness and other traits occur outside the period of feather formation [12]. For this reason, we measured the expression level of PCSK2 in the feather follicles [36] and feather spottiness in 75 nestlings ( 31 males, 44 females) at an age $(46.6 \pm 0.5 \mathrm{~d}$; range: $37-59)$ when feather spots had already been produced $(20-35 \mathrm{~d})$; sex was determined using molecular markers [69], and the day of hatching was determined by measuring the length of the left flattened wing from the bird's wrist to the tip of the longest primary soon after hatching [70]. For ethical reasons, we measured sleep at an earlier age to allow time for the small patch of feathers removed from the head for the EEG recordings to re-grow before fledging. Our approach did not appear to have any long-term adverse effects on the owls, as all of the birds fledged and recruitment into the breeding population in the following year (2012) was actually higher in owls that had their sleep recorded (26.3\%), than in those that had not (19.0\%). This research was approved by the Service Vétérinaire du Canton de Vaud (license 1508.5), and adhered to the National Institutes of Health standards regarding the care and use of animals in research. Statistical analyses were performed with the software program JMP 8.0.1. Tests were two-tailed with $p$-values $<0.05$ considered significant. Means are quoted \pm se.

\section{Rearing environment}

The birds were recorded in broods of $2-8$ individuals in their nest boxes (Figure 1d,e). Each nest box $(62 \times 56 \times$ $37 \mathrm{~cm}$ ) was hung (about 8 meters up) on the external wall of a barn surrounded by farmland and various habitats [71]. A $10 \times 15 \mathrm{~cm}$ door allowed entry of some natural light during the day. Presumably, the nestlings could also hear natural and human made noises. Ambient daily temperatures were obtained from the Swiss Meteorological Institute (MeteoSwiss) at a station in Payerne which is situated in the center of the study area. The mean daily temperature was $16.5 \pm 0.4^{\circ} \mathrm{C}$ (range $10.5-21.5^{\circ} \mathrm{C}$ ).

\section{Sleep recordings}

We recorded sleep in nestlings (31 males and 35 females from 29 nests) between $27-48 \mathrm{~d}$ of age $(38.2 \pm 0.55 \mathrm{~d})$. Nestlings in this age range have open eyes, but are still undergoing a large amount of brain development [72] and remain dependent upon parental provisioning of food. Each nestling was instrumented with a small data logger [73] (Neurologger2, www.vyssotski.ch/neurologger2) that recorded EEG activity (band-pass filtered $1-70 \mathrm{~Hz}$, first order) and head movements using a minimally-invasive electrode attachment method (see Additional file 1) initially developed for use in humans [74], and validated for use in owls [18]. In a subset of birds, simultaneous video recordings were obtained to relate EEG and accelerometer signals to specific behaviors (Additional file 1: Figure S1; Additional file 2: Video S1). EEG recordings were obtained between May and October 2011.

\section{Behavioral state scoring}

The last complete 24-h d of each recording was visually scored in 4 sec epochs for wakefulness, non-REM sleep, and REM sleep by an experienced investigator (NCR) blind to the age and pigmentation of the owls, as well as their PCSK2 expression levels. The 24-h period usually started several days after the owls were returned to their nest following logger attachment (mean, $65 \mathrm{~h} 55$ min; range, $21 \mathrm{~h}$ $15 \mathrm{~min}-92 \mathrm{~h} 29 \mathrm{~min}$ ). To determine whether variation in this latency influenced sleep, we performed linear mixed models with nest of rearing as the random variable and box-cox transformed latency as the independent variable. Latency was not significantly associated with the time spent in wakefulness, non-REM sleep, or REM sleep, nor the mean bout duration of any state (Pearson's correlations, $p$-values $>0.11$ ). Consequently, sleep normalized rapidly after return to the nest.

The percentage of the 24-h period spent in each state was calculated for each nestling. In addition, the duration of individual bouts of each state was calculated as the number of consecutive epochs spent in a given state. The mean bout duration was calculated for each state for each bird. Finally, we calculated the REM sleep latency as the elapsed 
time from sleep onset ( $\geq 4$ sec of non-REM or REM sleep) to the onset of REM sleep ( $\geq 4 \mathrm{sec}$ ) following bouts of wakefulness $\geq 4$ sec; i.e., when an owlet went directly from wakefulness to REM sleep the latency was zero. We also examined the REM sleep latency following only longer bouts of wakefulness ( 28 and $60 \mathrm{sec}$ ) and obtained similar results. The mean REM sleep latency was calculated for each nestling. The data presented in Figure 2 is available in Additional file 3.

\section{Measurement and genetics of eumelanin feather spotting}

In nestlings and their genetic parents (see below), we measured the number and diameter of eumelanin-based spots within a $60 \times 40 \mathrm{~mm}$ area of the breast. In nestlings, PCSK2 expression was measured in the same area. The number of black spots was strongly correlated with mean spot diameter within nestlings, and within breeding females and males $(0.88>r>0.47, p<0.006)$. For this reason, and because preliminary analyses showed that spot number and diameter were similarly associated with PCSK2 expression and sleep, we took the first principal component of a principal components analysis including spot number and mean spot diameter. Because PCSK2 expression did not differ between males and females (see Results) and also because females are on average spottier than males [70], we centered these groups separately by z-scoring. The first principal component explained $93.4 \%$ of the variance in nestlings (eigenvalue: 1.87), $73.3 \%$ in breeding females (eigenvalue: 1.47), and 92.9\% in breeding males (eigenvalue: 1.86). We define this first principal component as plumage "spottiness". The nestlings' age when the feathers were collected was not associated with spottiness measured in nestlings, nor their biological parents (two separate linear mixed models with nest of rearing as the random variable: $p$-values $>0.14)$.

The following steps were taken to isolate the genetic contribution to nestling spottiness. Although extra-pair paternity is very low in our population [75], in the present study we verified that the social parents of each offspring were the biological parents using six genetic markers (Ta204, Ta206, Ta216, Ta310, Ta413, and Ta414) [76]. In addition, to control for the potential impact that rearing conditions might have on the measured phenotypes, we performed a cross-fostering experiment at hatching by swapping half of the hatchlings between pairs of nests, thereby allocating genotypes randomly among rearing environments.

\section{Feather eumelanin spotting and $P C S K 2$ expression}

We measured PCSK2 expression using standard methods (see Additional file 1) in 75 cross-fostered nestlings from 26 families. PCSK2 expression was measured in 61 of the 66 individuals for which we assessed sleep.

\section{Additional files}

\begin{abstract}
Additional file 1: Table S1. Quantitative PCR primers and probes used to measure PCSK2 expression in feather follicles. Figure S1. Representative EEG and accelerometry recordings showing wakefulness, non-REM sleep, and REM sleep. Eight consecutive minutes are shown with 1 minute per panel (a-h). Additional file 2: Video S1 shows the corresponding behavior. The first minute starts with the owlet preening (a), as reflected in the high-frequency oscillations in the accelerometer recordings and corresponding EEG artifacts. The bird then spends an extended period (>3 min) looking around the box (a-e). The small abrupt changes in the accelerometer recordings correspond to head movements. Low-amplitude, high-frequency EEG activity indicative of wakefulness is evident between the head movements. Upon falling asleep (e), the rapid head movements stop, the eyes close, and the EEG shows high-amplitude, low-frequency waves indicative of non-REM sleep. The remaining panels (f-h) show alternations between non-REM and REM sleep. During REM sleep the EEG shows wakefulness-like activity, but the head remains still or falls gradually, and the bird's eyes remain closed. Similar behavior occurs in owlets without the EEG logger on their head (see bird on the right in Additional file 2: Video S1 at 16:27:52). Figure S2. EEG power density for wakefulness, non-REM sleep, and REM sleep. The three black lines mark significant differences ( $p<0.05$; two-tailed $t$ tests) between wakefulness and non-REM sleep ( $\mathrm{W}$ vs $\mathrm{N}$ ), wakefulness and REM sleep (W vs R), and non-REM and REM sleep ( $N$ vs R). Figure S3. Mean time spent in each state for all owls recorded on a given julian day and the corresponding mean temperature.
\end{abstract}

Additional file 2: Video S1. Eight minute video corresponding to the EEG and accelerometry recordings shown in Additional file 1: Figure S1. The bird is positioned in the left half of the frame. A second bird can be seen in the right half of the frame.

Additional file 3: File containing sleep data from Figure 2.

\section{Abbreviations}

ACTH: Adrenocorticotropic hormone; a-MSH: a-melanocyte-stimulating hormone; CLIP: Corticotropin-like intermediate lobe peptide; EEG: Electroencephalogram; HPA: Hypothalamic-pituitary-adrenal; HPT: Hypothalamic-pituitary-thyroid; icv: intracerebralventricularly; MCR1: Melanocortin 1 receptor; MC1R: Gene encoding MCR1; non-REM: nonrapid eye movement; PCSK2: Proprotein convertase subtilisin/kexin type 2 PCSK2: Gene encoding PCSK2; REM: Rapid eye movement.

\section{Competing interests}

The authors declare that they have no competing interests.

\section{Authors' contributions}

AR, A-LD, MFS, and NCR designed the study. MFS collected and NCR scored the neurophysiological data. A-LD quantified gene expression. AR performed the statistical analyses. IH collected biometric data from the owls. ALV developed and provided Neurologger $2 s$ and contributed to the figures. AR, A-LD, MFS, and NCR wrote the paper. A-LD and MFS contributed equally, as did AR and NCR. All authors discussed the results and commented on the manuscript. All authors read and approved the final manuscript.

\section{Acknowledgements}

The research was supported by the Max Planck Society and the Swiss National Science Foundation. We thank Paul Béziers, Simon Krenger, Hannes Richter, and Céline Simon for their assistance, and Dolores Martinez-Gonzalez for comments on the manuscript.

\section{Author details}

${ }^{1}$ Avian Sleep Group, Max Planck Institute for Ornithology, Eberhard-Gwinner-str.11, Seewiesen 82319, Germany. ${ }^{2}$ Department of Ecology and Evolution, University of Lausanne, Lausanne 1015, Switzerland. ${ }^{3}$ Institute of Neuroinformatics, University of Zürich and ETH Zürich, Zürich 8057, Switzerland.

Received: 7 May 2013 Accepted: 24 July 2013

Published: 26 July 2013 
References

1. Majerus MEN: Melanism: evolution in action. Oxford: Oxford University Press; 1998.

2. Mundy NI: A window on the genetics of evolution: MC1R and plumage colouration in birds. Proc R SOC B 2005, 272:1633-1640.

3. Makova K, Norton $\mathrm{H}$ : Worldwide polymorphism at the MC1R locus and normal pigmentation variation in humans. Peptides 2005, 26:1901-1908.

4. Mogil JS, Wilson SG, Chesler EJ, Rankin AL, Nemmani KV, Lariviere WR, Groce MK, Wallace MR, Kaplan L, Staud R, Ness TJ, Glover TL, Stankova M, Mayorov A, Hruby VJ, Grisel JE, Fillingim RB: The melanocortin-1 receptor gene mediates female-specific mechanisms of analgesia in mice and humans. Proc Natl Acad Sci USA 2003, 100:4867-4872.

5. McKinnon JS, Pierotti ME: Colour polymorphism and correlated characters: genetic mechanisms and evolution. Mol Ecol 2010, 19:5101-5125

6. van den Brink V, Dolivo V, Falourd X, Dreiss AN, Roulin A: Melanic colordependent antipredator behavior strategies in barn owl nestlings. Behav Ecol 2012, 23:473-480.

7. van den Brink V, Dreiss AN, Roulin A: Melanin-based coloration predicts natal dispersal in the barn owl, Tyto alba. Anim Behav 2007, 84:805-812.

8. Roulin A, Altwegg R: Breeding rate is associated with pheomelanism in male and with eumelanism in female barn owls. Behav Ecol 2007, 18:563-570.

9. Roulin A, Riols C, Dijkstra C, Ducrest A-L: Female plumage spottiness signals parasite resistance in the barn owl (Tyto alba). Behav Ecol 2001 12:103-110.

10. Almasi B, Roulin A, Korner-Nievergelt F, Jenni-Eiermann S, Jenni L: Coloration signals the ability to cope with elevated stress hormones: effects of corticosterone on growth of barn owls are associated with melanism. J Evol Biol 2012, 25:1189-1199.

11. Dreiss A, Henry I, Ruppli C, Almasi B, Roulin A: Darker eumelanic barn owls better withstand food depletion through resistance to food deprivation and lower appetite. Oecologia 2010, 164:65-71.

12. Roulin A, Ducrest A-L: Association between melanism, physiology and behaviour: a role for the melanocortin system. Eur J Pharmacol 2011 660:226-233.

13. Höglund $\mathrm{E}$, Balm PH, Winberg S: Skin darkening, a potential social signal in subordinate arctic charr (Salvelinus alpinus): the regulatory role of brain monoamines and pro-opiomelanocortin-derived peptides. J Exp Biol 2000, 203:1711-1721

14. Valatx JL, Cespuglio R, Paut L, Bailey DW: Genetic study of paradoxical sleep in mice. Connection with coloration genes. Waking Sleeping 1980, 4:175-183.

15. Leung C, Bergmann BM, Rechtschaffen A, Benca RM: Heritability of dark pulse triggering of paradoxical sleep in rats. Physiol Behav 1992, 52:127-131.

16. Daan S: How and why? The lab versus the field. Sleep Biol Rhythms 2011, 9:1-2.

17. Mirmiran M, Maas YG, Ariagno RL: Development of fetal and neonatal sleep and circadian rhythms. Sleep Med Rev 2003, 7:321-334.

18. Scriba MF, Harmening WM, Mettke-Hofmann C, Vyssotski AL, Roulin A Wagner $\mathrm{H}$, Rattenborg NC: Evaluation of two minimally-invasive techniques for electroencephalogram recording in wild or freely behaving animals. J Comp Physiol A 2013, 199:183-189.

19. Martin GR, Wilson K-J, Wild JM, Parsons S, Kubke MF, Corfield J: Kiwi forego vision in the guidance of their nocturnal activities. PLoS One 2007, 2:e198.

20. Rattenborg NC, Martinez-Gonzalez D, Roth TC 2nd, Pravosudov W: Hippocampal memory consolidation during sleep: a comparison of mammals and birds. Biol Rev Camb Philos Soc 2011, 86:658-691.

21. Roffwarg HP, Muzio JN, Dement WC: Ontogenetic development of the human sleep-dream cycle. Science 1966, 152:604-619.

22. Jouvet-Mounier D, Astic L, Lacote D: Ontogenesis of the states of sleep in rat, cat, and guinea pig during the first postnatal month. Dev Psychobiol 1970, 2:216-239.

23. Frank MG, Heller HC: Development of REM and slow wave sleep in the rat. Am J Physiol 1997, 272:R1792-R1799.

24. Thurber A, Jha SK, Coleman T, Frank MG: A preliminary study of sleep ontogenesis in the ferret (Mustela putorius furo). Behav Brain Res 2008, 189:41-51.

25. Astic $L$, Jouvet-Mounier D: Demonstration of paradoxical sleep in utero in guinea pigs. C R Acad Sci 1969, 269:2578-2581.

26. Ruckebusch Y: Development of sleep and wakefulness in the foetal lamb. Electroencephalogr Clin Neurophysiol 1972, 32:119-128.

27. Astic L, Sastre JP, Brandon AM: Polygraphic study of vigilance states in the guinea pig fetus. Physiol Behav 1973, 11:647-654.
28. Ibuka N: Ontogenesis of circadian sleep-wakefulness rhythms and developmental changes of sleep in the altricial rat and in the precocial guinea pig. Behav Brain Res 1984, 11:185-196.

29. Szeto HH, Hinman DJ: Prenatal development of sleep-wake patterns in sheep. Sleep 1985, 8:347-355.

30. Klein M, Michel $F$, Jouvet M: Etude polygraphique du sommeil chez les oiseaux. C R Soc Biol 1964, 158:99-103.

31. Saucier D, Astic L: Polygraphic study of sleep in young chickens at hatching, evolution at third and fourth days. Electroencephalogr Clin Neurophysiol 1975, 38:303-306.

32. Szymczak JT: Distribution of sleep and wakefulness in 24-h light-dark cycles in the juvenile and adult magpie, Pica pica. Chronobiologia 1987, 14:277-287.

33. Schlehuber CJ, Flaming DG, Lange GD, Spooner CE: Paradoxical sleep in the chick (Gallus domesticus). Behav Biol 1974, 11:537-546.

34. Szymczak JT: Influence of environmental temperature and photoperiod on temporal structure of sleep in corvids. Acta Neurobiol Exp 1989, 49:359-366.

35. Shaffery JP, Roffwarg HP, Speciale SG, Marks GA: Ponto-geniculo-occipitalwave suppression amplifies lateral geniculate nucleus cell-size changes in monocularly deprived kittens. Brain Res Dev Brain Res 1999, 114:109-119.

36. Yoshihara C, Tashiro Y, Taniuchi S, Katayama H, Takahashi S, Takeuchi S: Feather follicles express two classes of pro-opiomelanocortin (POMC) mRNA using alternative promoters in chickens. Gen Comp Endocrinol 2011, 171:46-51.

37. Hobson JA: REM sleep and dreaming: towards a theory of protoconsciousness. Nat Rev Neurosci 2009, 10:803-813.

38. Corner MA, Schadé JP, Sedlácek J, Stoeckart R, Bot AP: Developmental patterns in the central nervous system of birds. I. Electrical activity in the cerebral hemisphere, optic lobe and cerebellum. Prog Brain Res 1967, 26:145-192

39. Balaban E, Desco M, Vaquero JJ: Waking-like brain function in embryos. Curr Biol 2012, 22:852-861.

40. Speciale SG, Nowaczyk T, Jouvet M: Chick phasic bioelectric activity at the time of hatching and the effects of previous nialamide injection. Brain Res 1976, 101:148-154.

41. Speciale SG, Nowaczyk T, Jouvet M: A longitudinal study of bioelectric activity in the pre- and post-hatch chick. Dev Psychobiol 1976, 9:539-547.

42. Peters J, Vonderahe A, Schmid D: Onset of cerebral electrical activity associated with behavioral sleep and attention in the developing chick. J Exp Zool 1965, 160:255-261.

43. Blumberg MS, Karlsson KA, Seelke AM, Mohns EJ: The ontogeny of mammalian sleep: a response to Frank and Heller (2003). J Sleep Res 2005, 14:91-98.

44. Frank MG, Heller HC: Unresolved issues in sleep ontogeny: a response to Blumberg et al. J Sleep Res 2005, 14:98-101.

45. Solodkin M, Cardona A, Corsi-Cabrera M: Paradoxical sleep augmentation after imprinting in the domestic chick. Physiol Behav 1985, 35:343-348.

46. Heller HC, Graf R, Rautenberg W: Circadian and arousal state influences on thermoregulation in the pigeon. Am J Physiol 1983, 245:R321-R328.

47. Graf R, Heller HC, Sakaguchi S, Krishna S: Influence of spinal and hypothalamic warming on metabolism and sleep in pigeons. Am J Physiol 1987, 252:R661-R667.

48. Slominski AT, Zmijewski MA, Skobowiat C, Zbytek B, Slominski RM, Steketee JD: Sensing the environment: regulation of local and global homeostasis by the skin's neuroendocrine system. Adv Anat Embryol Cell Biol 2012. 212:1-115.

49. Opp MR, Obál F, Krueger JM: Effects of alpha-MSH on sleep, behavior, and brain temperature: interactions with IL 1. Am J Physiol 1988, 255:R914-R922.

50. Chastrette N, Cespuglio R, Lin YL, Jouvet M: Proopiomelanocortin (POMC)derived peptides and sleep in the rat. Part 2 - Aminergic regulatory processes. Neuropeptides 1990, 15:75-88.

51. Koo BB, Feng P, Dostal J, Strohl KP: Alpha-melanocyte stimulating hormone and adrenocorticotropic hormone: an alternative approach when thinking about restless legs syndrome? Mov Disord 2008, 23:1234-1242.

52. Wetzel W, Balschun D, Janke S, Vogel D, Wagner T: Effects of CLIP (corticotropin-like intermediate lobe peptide) and CLIP fragments on paradoxical sleep in rats. Peptides 1994, 15:237-241.

53. Wetzel W, Wagner T, Vogel D, Demuth HU, Balschun D: Effects of the CLIP fragment ACTH 20-24 on the duration of REM sleep episodes. Neuropeptides 1997, 31:41-45. 
54. Wetzel W, Wagner T, Balschun D: REM sleep enhancement induced by different procedures improves memory retention in rats. Eur J Neurosci 2003, 18:2611-2617.

55. Fuchs T, Siegel JJ, Burgdorf J, Bingman VP: A selective serotonin reuptake inhibitor reduces REM sleep in the homing pigeon. Physiol Behav 2006, 87:575-581.

56. Lamers WH, Mooren PG, Griep H, Endert E, Degenhart HJ, Charles R: Hormones in perinatal rat and spiny mouse: relation to altricial and precocial timing of birth. Am J Physiol 1986, 251:E78-E85.

57. Oh JD, Butcher LL, Woolf NJ: Thyroid hormone modulates the development of cholinergic terminal fields in the rat forebrain: relation to nerve growth factor receptor. Brain Res Dev Brain Res 1991, 59:133-142.

58. Howdeshell KL: A model of the development of the brain as a construct of the thyroid system. Environ Health Perspect 2002, 110(Suppl 3):337-348.

59. McNabb FM: The hypothalamic-pituitary-thyroid (HPT) axis in birds and its role in bird development and reproduction. Crit Rev Toxicol 2007, 37:163-193.

60. Powell MH, Nguyen HV, Gilbert M, Parekh M, Colon-Perez LM, Mareci TH, Montie E: Magnetic resonance imaging and volumetric analysis: Novel tools to study the effects of thyroid hormone disruption on white matter development. NeuroToxicology 2012, 33:1322-1329.

61. Seidah NG, Prat A: The biology and therapeutic targeting of the proprotein convertases. Nat Rev Drug Discov 2012, 11:367-383.

62. Marcinkiewicz M, Ramla D, Seidah NG, Chrétien M: Developmental expression of the prohormone convertases PC1 and PC2 in mouse pancreatic islets. Endocrinology 1994, 135:1651-1660.

63. Fernandez AM, Torres-Alemán I: The many faces of insulin-like peptide signaling in the brain. Nat Rev Neurosci 2012, 13:225-239.

64. Fox DL, Vella KR, Good DJ: Energy balance pathways converging on the Nhlh2 transcription factor. Front Biosci 2007, 12:3983-3993.

65. Iwaniuk AN, Nelson JE: Developmental differences are correlated with relative brain size in birds: a comparative analysis. Can J Zool 2003, 81:1913-1928.

66. Overington SE, Morand-Ferron J, Boogert N, Lefebvre L: Technical innovations drive the relationship between innovativeness and residual brain size in birds. Anim Behav 2011, 78:1001-1010.

67. Sol D, Székely T, Liker A, Lefebvre L: Big-brained birds survive better in nature. Proc Biol Sci 2007, 274:763-769.

68. Horne J: Why REM sleep? Clues beyond the laboratory in a more challenging world. Biol Psychol 2013, 92:152-168.

69. Py I, Ducrest A-L, Duvoisin N, Fumagalli L, Roulin A: Ultraviolet reflectance in a melanin-based plumage trait is heritable. Evol Ecol Res 2006, 8:483-491.

70. Roulin A: Proximate basis of the covariation between a melanin-based female ornament and offspring quality. Oecologia 2004, 140:668-675.

71. Frey C, Sonnay C, Dreiss A, Roulin A: Habitat, breeding performance, diet and individual age in Swiss Barn Owls (Tyto alba). J Ornithol 2011, 152:279-290.

72. Köppl C, Futterer E, Nieder B, Sistermann R, Wagner H: Embryonic and posthatching development of the barn owl (Tyto alba): reference data for age determination. Dev Dyn 2005, 233:1248-1260.

73. Vyssotski AL, Dell'Omo G, Dell'Ariccia G, Abramchuk AN, Serkov AN, Latanov AV, Loizzo A, Wolfer DP, Lipp HP: EEG responses to visual landmarks in flying pigeons. Curr Biol 2009, 19:1159-1166.

74. Ives JR: New chronic EEG electrode for critical/intensive care unit monitoring. J Clin Neurophysiol 2005, 22:119-123.

75. Roulin A, Muller W, Sasvari L, Dijkstra C, Ducrest A-L, Riols C, Wink M, Lubjuhn T: Extra-pair paternity, testes size and testosterone level in relation to colour polymorphism in the barn owl Tyto alba. J Avian Biol 2004, 35:492-500.

76. Burri R, Antoniazza S, Siverio F, Klein A, Roulin A, Fumagalli L: Isolation and characterization of 21 microsatellite markers in the barn owl (Tyto alba). Mol Ecol Resources 2008, 8:977-979.

\section{doi:10.1186/1742-9994-10-42}

Cite this article as: Scriba et al:: Linking melanism to brain development: expression of a melanism-related gene in barn owl feather follicles covaries with sleep ontogeny. Frontiers in Zoology 2013 10:42.

\section{Submit your next manuscript to BioMed Central and take full advantage of:}

- Convenient online submission

- Thorough peer review

- No space constraints or color figure charges

- Immediate publication on acceptance

- Inclusion in PubMed, CAS, Scopus and Google Scholar

- Research which is freely available for redistribution

Submit your manuscript at www.biomedcentral.com/submit
C BioMed Central 